\title{
Localization of the Umbilical Catheter by Post-mortem Measurement
}

\author{
PETER M. DUNN \\ From the Royal Hospital for Sick Children, Bristol
}

During the first two weeks of life the umbilical vessels provide ready access to the main vascular compartments of the body. Catheterization is simple, relatively free from complications, and does not involve the sacrifice of a large vessel. Although in the past this procedure has been used mainly either for exchange transfusion, for giving fluids and drugs, or for obtaining blood samples, it is now used increasingly for the investigation of congenital anomalies and for research into the physiological changes taking place at, and soon after, birth. In order to interpret these investigations it becomes essential to know exactly where the tip of the catheter is lying. Radiological localization, while reliable, carries with it the risks of irradiation. The use of a continuous blood pressure recording and the repeated sampling of blood for estimation of oxygen saturation are methods which, though safer, require equipment and expertise that make them a considerable undertaking in themselves. Also at a time of life when the foetal channels are still patent, transitory shunts and abrupt changes in blood pressure may occasionally make information obtained by these methods difficult to interpret. The remaining method, based on knowledge of the length of catheter passed beyond the umbilical ring, has been widely used. However, remarkably little information has been reported on the interpretation of this measurement in terms of actual localization of the catheter tip. Some post-mortem studies have been reported but they have been based on few examinations and have not attempted to relate catheter measurements with the actual size of the infant.

The present study is intended both to draw attention to and to make a start at filling this small but important gap in our knowledge.

\section{Method}

Fifty infants without external evidence of congenital malformation were examined at necropsy; 19 were

Received June 20, 1965. stillborn (no maceration), and the remaining 31 had died during the first week of life. The birth weight of these infants ranged from 680 to $4,027 \mathrm{~g}$. and their length of gestation from 26 to 44 weeks.

A number of external measurements, which included the head circumference, crown-rump length, crown-heel or total length, and shoulder-umbilicus length, were recorded. (The shoulder-umbilicus length was defined as the distance between the top of the shoulder over the lateral end of the clavicle and a point vertically beneath it that was level with the centre of the umbilicus.)

The cadavers were dissected in such a way as to allow palpation of the heart and great vessels without displacing them or altering the position of the umbilicus in relation to the rest of the body. Attempts were then made to catheterize the umbilical vessels using a Portex F.G. 6 umbilical catheter; the finer F.G. 4 size was used for the smallest infants.

Measurement of the length of catheter that had to be passed beyond the umbilical ring to reach various anatomical points within the body was made in this way; the catheter was first passed beyond the point and was then gently withdrawn until its tip could be felt by the palpating finger; it was then grasped by a marker at the umbilical ring and withdrawn from the body so that the distance between the marker and the catheter tip could be measured. This manœuvre was repeated at least once for each anatomical point. It was important that the cadaver should be warm when undertaking these investigations, as otherwise the tissues tended to be stiff and unyielding and the polythene catheter lost its pliability. Rewarming of the cadaver was achieved by preliminary immersion in hot water.

The course of the umbilical vessels in the infant at birth is shown in Fig. 1. The anatomical points on which the umbilical catheter measurements were based are shown in this figure and are named and defined in the following way.

\section{Umbilical vein}

V1. 'The diaphragm': the inferior vena cava immediately above the diaphragm as it enters the pericardial cavity.

V2. 'The left atrium': the cavity of the left atrium by the foramen ovale; (the correct positioning of the palpating finger and thumb had been ascertained in previous dissections). 


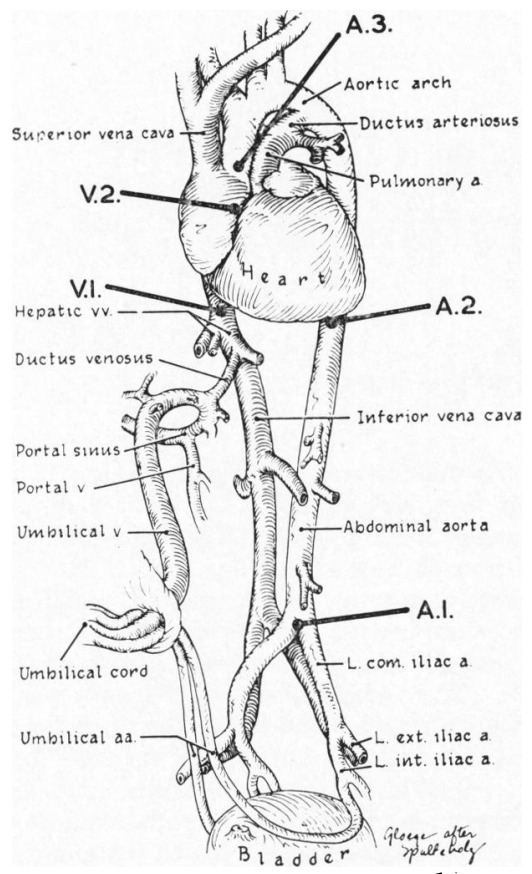

FIG. 1.-The course of the neonatal circulation at birth showing the anatomical points (see text) on which the catheter measurements were based. (Based on an illustration by Sapin, Linde, and Emmanouilides (1963), by courtesy of the Editor of Pediatrics.)

\section{Umbilical artery}

A1. 'The bifurcation of the aorta': this term is selfexplanatory.

A2. 'The diaphragm': the aorta immediately above the diaphragm (level with V1).

A3. 'The aortic valves': this term is self-explanatory.
A study was also made of the maximum length of catheter which might be fed into the umbilical vein at the umbilicus, in relation to the route it took within the body. The latter often varied or could be made to vary between one catheterization and another on the same infant. This measurement must be interpreted with great caution as it included the length of catheter which, in a few cases, became curled within the heart. The degree of 'curling' depends on chance and also on the resilience of the catheter which, in the case of polythene, varies with the temperature. Therefore in the still somewhat hypothermic cadavers investigated in this study, 'curling' of the catheter was probably less in evidence than it would have been in vivo.

\section{Results}

Analysis of the findings of this study showed that the best correlation was obtained when the length of catheter passed to reach any given point was plotted against either the total length or the shoulderumbilicus length of the infant. For the sake of brevity these two comparisons alone will be reported.

The length of umbilical vein catheter required to reach the inferior vena cava just above the diaphragm ranged from $5 \mathrm{~cm}$. in the smallest infants to $10 \cdot 5 \mathrm{~cm}$. in the largest; that required to reach the left atrium similarly varied from $6 \cdot 25 \mathrm{~cm}$. to $12.75 \mathrm{~cm}$. The relation between these results and the total or shoulder-umbilicus length of these infants may be seen in Fig. 2 and Fig. 3. The mean length of catheter required to reach these two points is expressed in Table $I$ as percentages of the two external measurements.

During the course of umbilical vein catheterization it was found possible to persuade the catheter to traverse the ductus venosus in $86 \%$ of the cases and the foramen ovale in $70 \%$. A momentary resistance

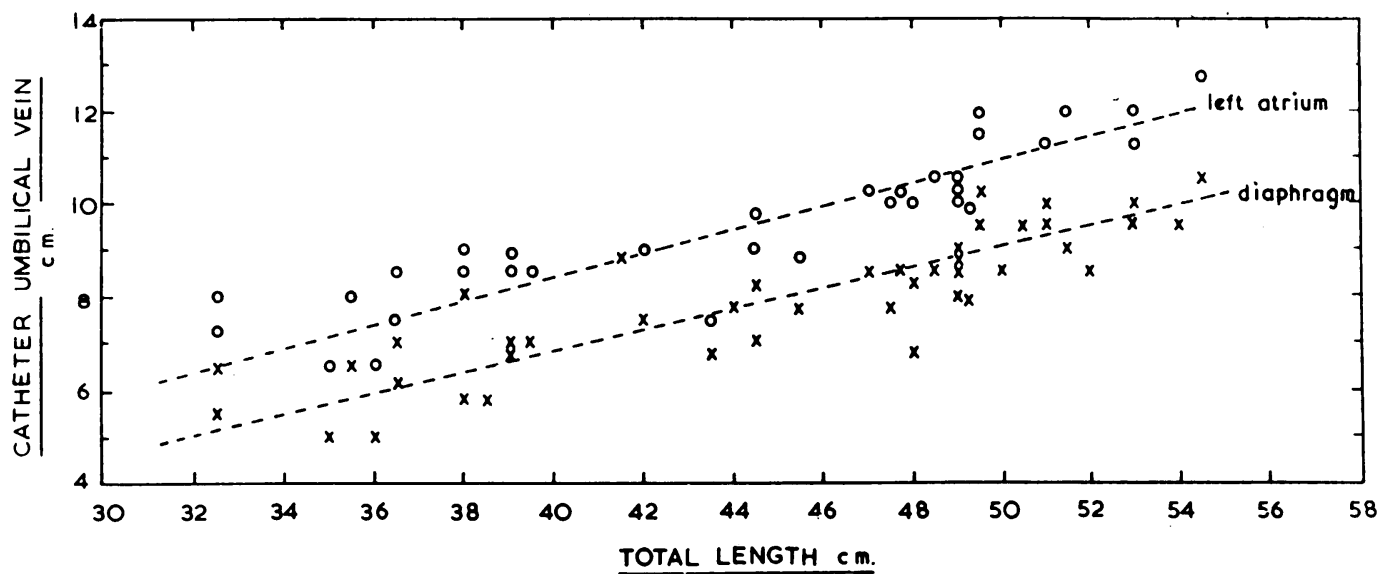

FIG. 2.-The relation between the length of catheter inserted into the umbilical vein in order to reach the 'diaphragm' $(r)$ and the 'left atrium' ( 0 ) (see text), and the total body length of an infant. 


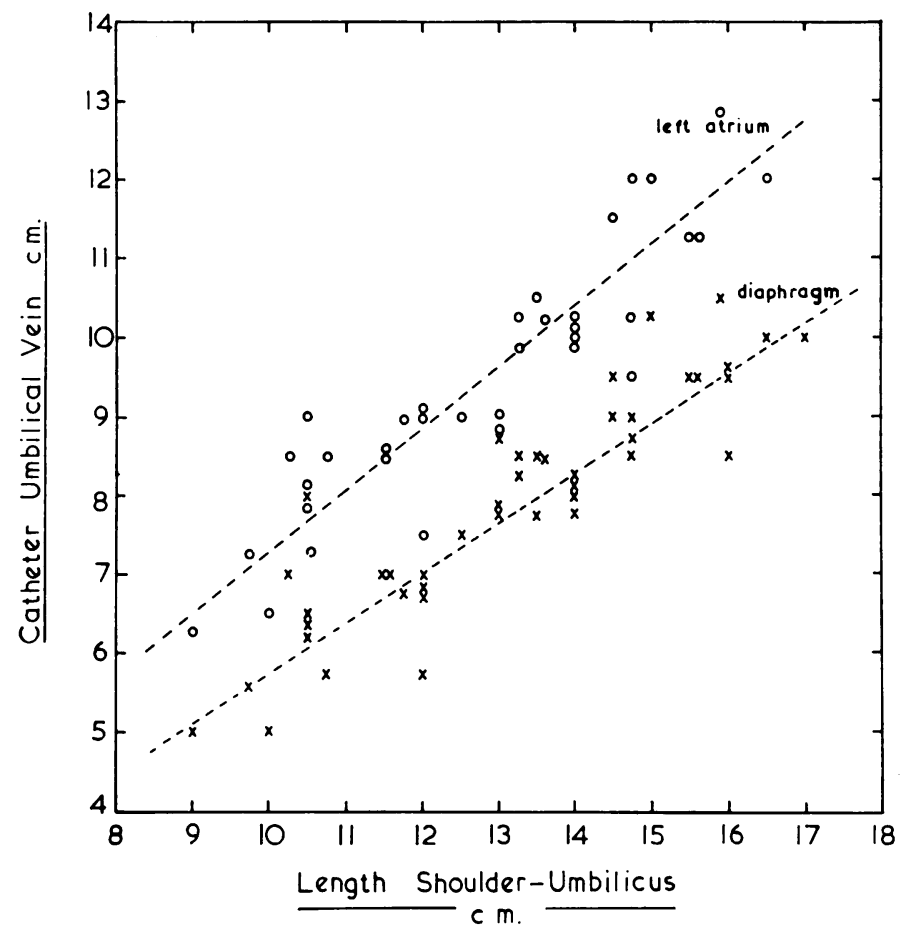

FIG. 3.-The relation between the length of catheter inserted into the umbilical vein in order to reach the 'diaphragm' $(x)$ and the 'left atrium' (o) (see text), and the shoulder-umbilicus length of an infant.

was frequently but not always felt as the catheter tip entered the ductus venosus. This resistance was palpable when the catheter had been passed a distance of 1 to $2 \cdot 5 \mathrm{~cm}$. less than that subsequently shown to be necessary to reach the inferior vena cava at the level of the diaphragm.

The mean maximum length of catheter that might be inserted into the umbilical vein is related in

TABLE I

Mean Length of Umbilical Catheter Required to Reach Various Anatomical Points (see text), Expressed as Percentages of the Infants' Total and ShoulderUmbilicus Lengths

\begin{tabular}{|c|c|c|c|}
\hline Anatomical Points & $\begin{array}{c}\text { No. of } \\
\text { Observa- } \\
\text { tions }\end{array}$ & $\begin{array}{c}\text { Total or } \\
\text { Crown-heel } \\
\text { Length }\end{array}$ & $\begin{array}{l}\text { Shoulder- } \\
\text { umbilicus } \\
\text { Length }\end{array}$ \\
\hline $\begin{array}{l}\text { Umbilical vein } \\
\text { V1. The diaphragm } \\
\text { V2. The left atrium }\end{array}$ & $\begin{array}{l}43 \\
35\end{array}$ & $\begin{array}{r}17 \cdot 6 \\
21 \cdot 4\end{array}$ & $\begin{array}{l}60 \cdot 0 \\
74 \cdot 3 \\
\end{array}$ \\
\hline $\begin{array}{l}\text { Umbilical artery } \\
\text { A1. Bifurcation of the aorta } \\
\text { A2. The diaphragm } \\
\text { A3. Aortic valves .. }\end{array}$ & $\begin{array}{l}26 \\
26 \\
24\end{array}$ & $\begin{array}{l}16 \cdot 5 \\
31 \cdot 3 \\
47 \cdot 5\end{array}$ & $\begin{array}{r}55 \cdot 8 \\
106 \cdot 4 \\
159 \cdot 9\end{array}$ \\
\hline
\end{tabular}

Table II to the final position of the catheter tip. Measurements are expressed as percentages of the total and the shoulder-umbilicus lengths. Inspection of the individual results allow two generalizations to be made:

(1) The catheter may always be passed a greater distance if it traverses the ductus venosus than if it does not.

\section{TABLE II}

Mean Maximum Length of Umbilical Vein Catheter Passed According to Location of Catheter Tip, When no further Catheter could be Passed through the Umbilicus, Expressed as Percentages of the Infants' Total and Shoulder-Umbilicus Lengths

\begin{tabular}{|c|c|c|c|}
\hline Site of Catheter Tip & $\begin{array}{l}\text { No. of } \\
\text { Observa- } \\
\text { tions }\end{array}$ & $\begin{array}{c}\text { Total or } \\
\text { Crown-heel } \\
\text { Length }\end{array}$ & $\begin{array}{l}\text { Shoulder- } \\
\text { umbilicus } \\
\text { Length }\end{array}$ \\
\hline 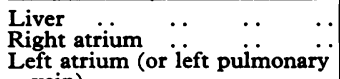 & $\begin{array}{r}13 \\
5\end{array}$ & $\begin{array}{r}17 \cdot 9 \\
27 \cdot 6\end{array}$ & $\begin{array}{r}60 \cdot 4 \\
92 \cdot 9\end{array}$ \\
\hline vein) Beyond the superior vena cava & $\begin{array}{l}33 \\
14\end{array}$ & $\begin{array}{l}27 \cdot 1 \\
40\end{array}$ & $\begin{array}{r}90 \cdot 3 \\
136 \cdot 6\end{array}$ \\
\hline
\end{tabular}




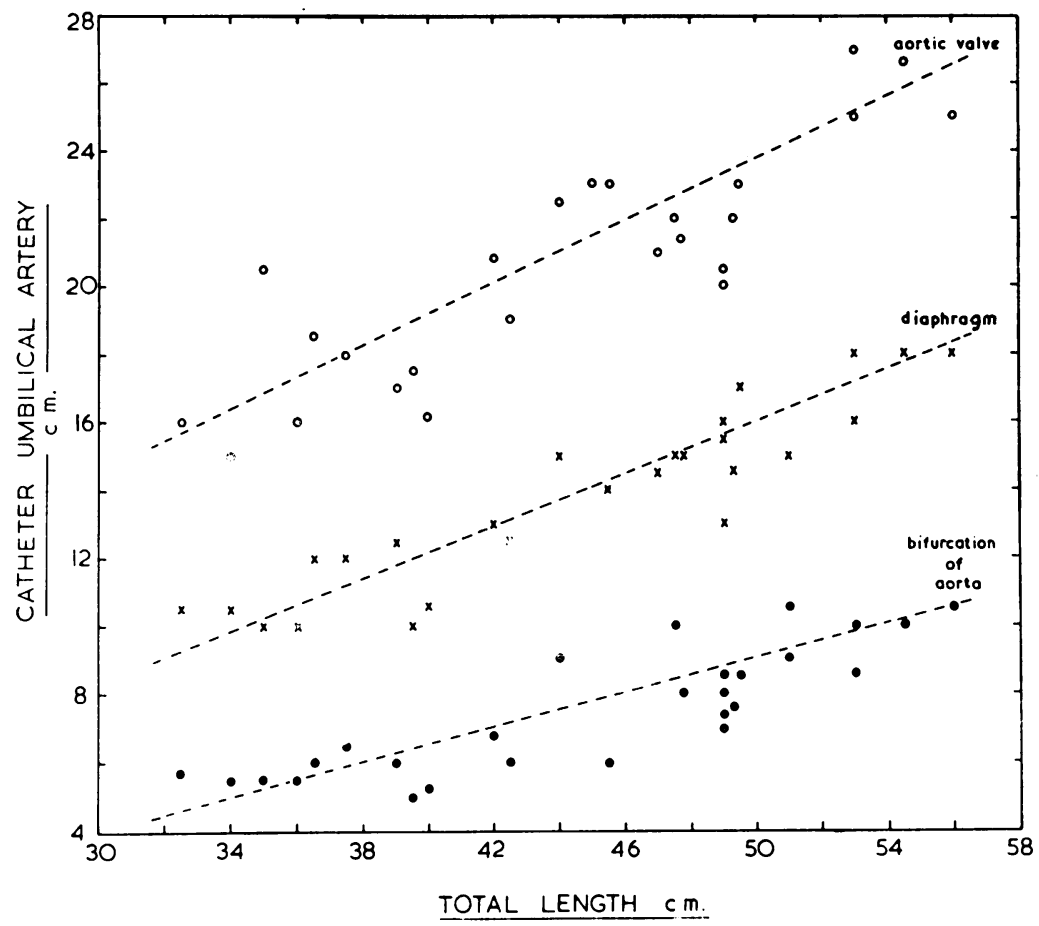

FIG. 4.-The relation between the length of catheter inserted into the umbilical artery in order to reach the bifurcation of the aorta, the 'diaphragm', or the aortic valves (see text), and the total body length of an infant.

(2) If the catheter is inserted into the umbilical vein a distance greater than $23 \%$ of the total body length or $80 \%$ of the shoulder-umbilicus length of an infant, then it has passed through the ductus venosus. The generalization may be proved false on the very rare occasions on which retrograde catheterization of the portal and either splenic or superior mesenteric vein takes place, or when the catheter becomes folded on itself within the portal system.

The length of umbilical artery catheter required to reach the bifurcation of the aorta ranged from 5.5 to $10 \mathrm{~cm}$.; to reach the diaphragm, from 10 to $18 \mathrm{~cm}$.; and to reach the aortic valves, from 15 to $27 \mathrm{~cm}$. The relation between these results and the total or shoulder-umbilicus length of these infants may be seen in Fig. 4 and Fig. 5 . It should be noted that one measurement, that of the length of catheter required to reach the aortic valves in one of the smallest infants, is likely to be inaccurate; the probable explanation, only appreciated later in the study, was that the F.G. 4 catheter used in this case had become doubled within the aorta. This tended to happen with the finer catheter if its tip became impacted in the left subclavian artery; as more catheter was passed it became kinked and then continued on round the aortic arch folded upon itself.

The mean length of catheter required to reach each of the three anatomical points on the aorta is expressed in Table $I$ as a percentage of the one or other external measurement.

Umbilical artery catheterization was successful in just over $50 \%$ of cases. Failure was usually due to resistance at the junction between the umbilical and the internal iliac arteries.

The relation between the internal and external measurements is shown in Fig. 2-5. The linear correlation when the shoulder-umbilicus length is used is better than that obtained for the total length. The explanation for this and for some of the scatter seen in these figures lies in the inconstant relationship between partial and total body length; this is demonstrated in Fig. 6 in which the two external measurements are plotted against each other. On the average, however, the shoulder-umbilicus length was found to be equal to $29.5 \%$ of the total length of the infant.

Although the method of measurement used in this study was relatively crude, it was found that 
individual measurements, when repeated for any particular land mark, rarely differed by more than $0.5 \mathrm{~cm}$.

\section{Discussion}

The present study demonstrates the importance of the relation between the infant's size and the length of umbilical catheter required to reach any particular anatomical site in the vascular system. It also provides some information on the limits within which the individual measurements may range. However, many more infants require to be studied before this information can be considered complete.

The main justification for reporting this small study lies in the fact that the information already available on this subject is even more inadequate, is often conflicting, and may be misleading. For instance van Loghem, van Bolhuis, Soeters, and Veeneklaas (1949) state that 'when the catheter has been inserted to a length of about $12-14 \mathrm{~cm}$. it has reached the vena cava inferior'. Yet in the present study it was found that even in the largest infants $10.5 \mathrm{~cm}$. of catheter were sufficient to reach the inferior vena cava above the diaphragm. Again, Jegier, Blankenship, and Lind (1963) in a study of the venous pressure in the first hour of life, introduced their umbilical vein catheters to a distance of $12-15 \mathrm{~cm}$. from the umbilicus. Their own two post-mortem measurements confirm the findings of the present study and suggest that their catheters are likely to have entered the heart, though it is not

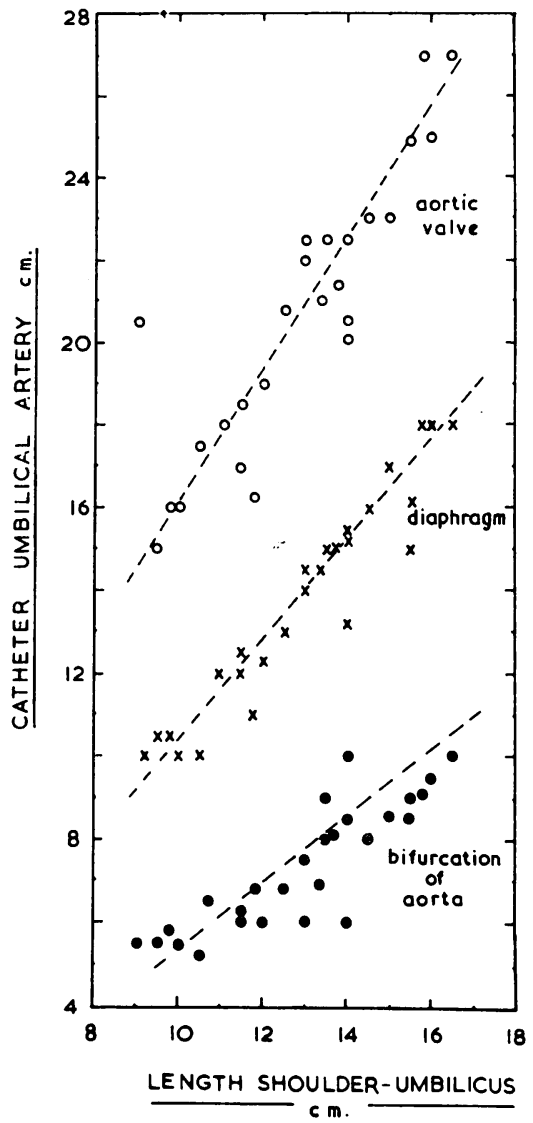

FIG. 5.-The relation between the length of catheter inserted into the umbilical artery in order to reach the bifurcation of the aorta, the 'diaphragm', or the aortic valves (see text), and the shoulder-umbilicus length of an infant.

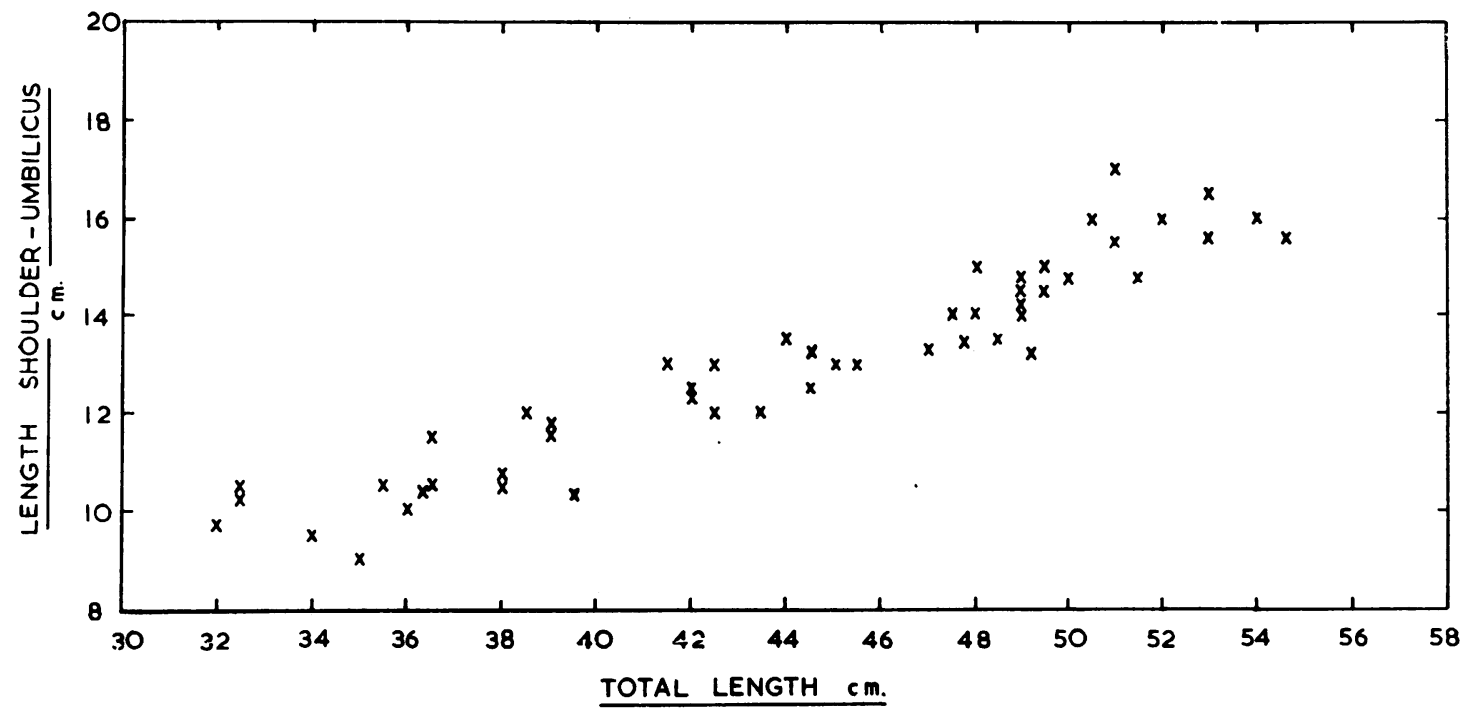

FIG. 6.-The relation between the shoulder-umbilicus length (see text) and the total body length of 50 infants dying in the perinatal period. 
possible from their measurements alone to determine whether the tip in any particular case would have been lying in the right or left atrium, left pulmonary vein, or superior vena cava. It is only fair to add that these workers also obtained a blood sample to insure that the catheter tip was placed in a venous channel and had not slipped into the left atrium'.

Another point of interest emerged during these investigations. It was found that the umbilical artery catheter passed up round the convexity of the aortic arch; frequently its tip became impacted in the left subclavian artery. In no case did it pass spontaneously through the ductus arteriosus. This finding stands in contrast to the experience of Moss, Emmanouilides, and Duffie (1963) who have succeeded in catheterizing the ductus arteriosus in over $60 \%$ of their attempts. However, their investigations were carried out on living infants, and it is possible that this accounts for their different experience.

Knowledge of the whereabouts of the umbilical catheter tip is also important to the clinician concerned with exchange transfusion. During this procedure relatively enormous volumes of donor blood are injected rapidly into the infant. This blood is in a highly unphysiological state; it is often chilled, has a $p \mathrm{H}$ of about $6 \cdot 6$, a high serum potassium, and, if citrated, an absence of ionized calcium. If this blood is injected into the umbilical vein or portal sinus then a high proportion will be likely to pass through the portal hepatic capillary bed. This appears to be most undesirable for, at this time of life, hepatic function is the critical factor determining the serum bilirubin level and the need for further exchange transfusions.

If, on the other hand, the catheter is passed too far beyond the ductus venosus it may enter the left side of the heart. Unphysiological donor blood will now have little opportunity for mixing with and being diluted by that of the infant before it reaches the vital coronary and cerebral circulations. It is not improbable that this mechanism is responsible for the sudden unexplained collapse and death of infants during exchange transfusion reported by some centres. A further danger of unintentional cardiac catheterization is that the thin membranous valve covering the foramen ovale may be damaged; at necropsy, using a fine and somewhat pointed catheter, perforation of this valve was achieved (though not easily) with pressure applied on the catheter at the umbilicus.

A third alternative, and the one favoured by the present writer, is to position the catheter tip in the inferior vena cava or in the ductus venosus proximal to its distal constriction. This may be achieved by both attention to the length of catheter passed in relation to the size of the infant, and by noting the momentary resistance felt as the catheter tip enters the ductus venosus from the portal sinus. This siting of the catheter tip has the advantage that the hepatic parenchyma is not exposed to an influx of unphysiological blood, while at the same time the latter still has an adequate chance of mixing with the infant's own blood as it circulates through the pulmonary capillary bed. However, it is important that the central venous pressure should not be raised unduly by too rapid an infusion; should this happen, the foramen ovale, as yet only functionally closed, may reopen to permit a right-to-left shunt of unphysiological blood. A further advantage of this position stems from the fact that the blood flow in the inferior vena cava is faster and of a greater volume than that in the portal sinus; hence, clotting round the catheter tip will be less likely to occur, blood will be easier to withdraw, and the efficiency of the 'exchange' will be greater. At the same time the portal vascular bed is spared the frequent intermittent distension which is inevitable when the catheter tip lies distal to the ductus venosus. It is not unreasonable to suppose that this distension is an important cause of the restlessness and discomfort exhibited by some infants during the injection of blood. The inferior vena cava, on the other hand, is specially designed to accommodate large and varying volumes of blood (Scholer, 1965).

\section{Summary}

A post-mortem study concerning the length of catheter required to be passed up the umbilical vessels in order to reach various anatomical sites within the body is reported in relation to the external measurements of 50 infants dying during the perinatal period.

The fundamental importance of knowledge of the whereabouts of the umbilical catheter in both clinical and research work is emphasized. In particular, the significance of the position of the catheter tip during exchange transfusion is discussed and the reasons given for believing that it should be sited in the inferior vena cava.

I wish to thank Professor A. V. Neale for reading the manuscript and for his encouragement. This investigation was made while working in a research capacity for the United Bristol Hospitals. It is a pleasure to thank Dr. F. J. W. Lewis and Dr. N. J. Brown for providing the necessary facilities in the Department of Pathology of Southmead General Hospital. I am also grateful to the Department of Medical Photography, Bristol Royal 
Infirmary for the illustrations, to Miss J. Powell and

Mrs. D. Watts for their help, and to the Medical Research Council who, by their financial support, made this assistance possible.

\section{REFERENCES}

Jegier, W., Blankenship, W., and Lind, J. (1963). Venous pressure in the first hour of life and its relationship to placental transfusion. Acta paediat. (Uppsala), 52, 485.
Moss, A. J., Emmanouilides, G., and Duffie, E. R., Jr. (1963) Closure of the ductus arteriosus in the newborn infant. Pediatrics, 32, 25.

Sapin, S. O., Linde, L. M., and Emmanouilides, G. C. (1963) Umbilical vessel angiocardiography in the newborn infant. ibid., 31, 946.

Scholer, H. (1965). Fundamental considerations on blood volume. Physiologic and clinical aspects. Amer. Heart f., 69, 701.

van Loghem, J. J., van Bolhuis, J. H., Soeters, J. M., and Veeneklaas, G. M. H. (1949). Treatment of 160 cases of erythroblastosis foetalis with replacement transfusion. Brit. med. F., 2, 49. 